\title{
ESTABELECIMENTO, MULTIPLICAÇÃO E ALONGAMENTO in vitro DE Eucalyptus benthamii Maiden \& Cambage $x$ Eucalyptus dunnii Maiden ${ }^{1}$
}

Gilvano Ebling Brondani ${ }^{2}$, Leonardo Ferreira Dutra ${ }^{3}$, Fernando Grossi ${ }^{4}$, Ivar Wendling ${ }^{5}$ e Jefferson Hornig ${ }^{2}$

\begin{abstract}
RESUMO - Neste trabalho foram testadas diferentes concentrações de cloro ativo (NaOCl) na assepsia de explantes para o estabelecimento in vitro, bem como benzilaminopurina (BAP) e ácido naftalenoacético (ANA) para a multiplicação e alongamento de Eucalyptus benthamii x Eucalyptus dunnii. As minicepas fornecedoras de propágulos para introdução in vitro foram conduzidas em minijardim clonal sob sistema semi-hidropônico. Segmentos nodais dos clones H12, H19 e H20 foram desinfestados com 0,5; 1,0; 1,5; e 2,0\% (v/v) de cloro ativo durante 10 min e inoculados em meio de cultura MS. Na obtenção de brotações múltiplas, utilizou-se o meio de cultura $1 / 2 \mathrm{MS}$ suplementado com $0 ; 0,25 ; 0,50 ; 0,75 ; \mathrm{e} 1,0 \mathrm{mg} \mathrm{L}^{-1}$ de BAP. Na fase de alongamento, utilizou-se o meio de cultura 1/2MS com $0 ; 0,25 ; 0,50 ; 0,75 ;$ e $1,0 \mathrm{mg} \mathrm{L}^{-1}$ de ANA. Não houve interação entre os fatores estudados, obtendo-se $45 \%, 46 \%$ e $66 \%$ de estabelecimento do clone H12, H19 e H20, respectivamente. A concentração de BAP que resultou na maior proliferação de gemas axilares para o clone H12 aos 60 dias foi estimada na faixa de 0,25 e $0,30 \mathrm{mg} \mathrm{L}^{-1}$. Aos 60 dias, a faixa entre 0,25 e $0,75 \mathrm{mg} \mathrm{L}^{-1}$ de ANA promoveu o maior número de brotações alongadas do clone $\mathrm{H} 12$.
\end{abstract}

Palavras-chave: Assepsia, segmento nodal, ANA, BAP e sistema semi-hidropônico.

\section{ESTABLISHMENT, MULTIPLICATION AND ELONGATION in vitro OF Eucalyptus benthamii Maiden \& Cambage $x$ Eucalyptus dunnii Maiden}

\begin{abstract}
This work aimed to evaluate different concentrations of active chlorine ( $\mathrm{NaOCl}$ ) in explant asepsis for the establishment in vitro as well as of benzylaminopurine (BAP) and naphthalene acetic acid (NAA) in the multiplication and elongation of Eucalyptus benthamii $x$ Eucalyptus dunnii. Ministumps, which supply shoots for introduction in vitro, were cultivated in a clonal mini garden under semi-hydroponic system. Nodal segments of clones H12, $\mathrm{H} 19$ and $\mathrm{H} 2 \mathrm{O}$ were disinfested with 0.5, 1.0, 1.5 and $2.0 \%(\mathrm{v} / \mathrm{v})$ of active chlorine during 10 minutes and inoculated in MS medium. In the multiplication phase, culture $1 / 2 M S$ medium supplemented with $0,0.25,0.50,0.75$ and $1.0 \mathrm{mg} \mathrm{L}^{-1}$ of BAP was used. In the elongation phase, $1 / 2 \mathrm{MS}$ medium supplemented with $0,0.25,0.50,0.75$ and $1.0 \mathrm{mg} \mathrm{L^{-1 }}$ of NAA was used. No interaction occurred between the studied levels, with $45 \%, 46 \%$ and $66 \%$ of establishment of clones $\mathrm{H1}$, $\mathrm{H} 19$ and $\mathrm{H} 2 \mathrm{O}$, respectively. The BAP concentration that resulted in the highest axillary's bud proliferation for clone $H 12$ at 60 days was estimated in the range of 0.25 to $0.30 \mathrm{mg} \mathrm{L}^{-1}$. At 60 days, the range between 0.25 to $0.75 \mathrm{mg} \mathrm{L}^{-1}$ of NAA, promoted the highest number of elongated shoots for H12 clone.
\end{abstract}

Keywords: Asepsis, nodal segment, NAA, BAP and semi-hydroponic system.

\footnotetext{
${ }^{1}$ Recebido em 27.08.2007 e aceito para publicação em 26.01.2009.

${ }^{2}$ Programa de Pós-Graduação em Engenharia Florestal da Universidade Federal do Paraná(UFPR). E-mail: <gebrondani@ yahoo.com.br>, $<$ jhaz@ufpr.br>.

${ }^{3}$ EmpresaBrasileirade PesquisaAgropecuária(EMBRAPA),CentrodePesquisaAgropecuáriadeClimaTemperado.E-mail: <leo@cpact.embrapa.br>.

${ }^{4}$ Departamento de Ciências Florestais da UFPR. E-mail: <f_grossi@ufpr.br>.

${ }^{5}$ Empresa Brasileira de Pesquisa Agropecuária (EMBRAPA),Centro Nacional de Pesquisa de Florestas. E-mail: <ivar@ cnpf.embrapa.br>.
} 


\section{INTRODUÇÃO}

O gênero Eucalyptus inclui a maioria das espécies florestais utilizadas no estabelecimento de plantações em áreas tropicais e subtropicais do mundo, sendo a clonagem de genótipos superiores uma alternativa para o estabelecimento de plantios clonais (ALVES et al., 2004). O grande potencial das espécies de Eucalyptus em produzir madeira e fibra para polpa e papel fez que o gênero ganhasse grande importância comercial, tornando-se alvo da propagação in vitro e manipulação genética (MERKLE e NAIRN, 2005).

As práticas e técnicas silviculturais convencionais contribuíram significativamente para melhoria das espécies florestais e continuarão a ter impacto substancial na produtividade (JOSHI et al., 2003; NEHRA et al., 2005). O desenvolvimento da clonagem com espécies puras e de híbridos interespecíficos do gênero Eucalyptus, por meio do enraizamento de estacas, foi o marco inicial para a propagação vegetativa assumir posição de destaque e despertar o interesse de empresas e pesquisadores (TITON et al., 2003). Os ganhos em homogeneidade, produtividade e adaptabilidade dos plantios clonais e a obtenção destes em um período relativamente curto justificam o processo de clonagem (CAMPINHOS et al., 1999).

No Brasil, os reflorestamentos são realizados com mudas de clones selecionados para as características silviculturais e tecnológicas de interesse de cada empresa (DEL PONTE et al., 2001). São clonados principalmente híbridos naturais de Eucalyptus, e as espécies potenciais para melhorar as características da madeira e adaptação dos clones vêm sendo introduzidas nos programas de hibridação das empresas (CAMPINHOS et al., 1999).

Atualmente, a clonagem do gênero é realizada, principalmente, por miniestaquia, porém muitas empresas florestais utilizam a cultura de tecidos para produção massal de genótipos selecionados através de sucessivas gerações (WATT et al., 2003). Entre as técnicas de cultura de tecidos de plantas, a micropropagação tem sido a mais difundida e com aplicações práticas comprovadas (XAVIER e COMÉRIO, 1996; XAVIER e COMÉRIO, 1997).

Na micropropagação, a alta taxa de multiplicação acelera os programas de propagação clonal e possibilita a clonagem de híbridos de Eucalyptus de alto valor e difícil enraizamento, e um dos fatores mais críticos dessa técnica refere-se ao sucesso na fase de desinfestação dos explantes. Grattapaglia e Machado
(1998) destacaram que a dificuldade maior nessa etapa reside em se obter tecido descontaminado, sem conduzilo à morte quando isolado, em que os pré-tratamentos aplicados à planta-matriz são determinantes para o sucesso do empreendimento. Segundo esses autores, várias substâncias com ação germicida são utilizadas para fazer a desinfestação dos explantes, destacandose o etanol e os compostos à base de cloro.

As citocininas são indispensáveis para a quebra de dominância apical e indução de proliferação de gemas axilares, sendo o tipo de citocinina e sua concentração os fatores que mais influenciam o sucesso da multiplicação in vitro. Na literatura, as concentrações de citocininas para multiplicação de Eucalyptus geralmente variam de 0,1 a 5,0 $\mathrm{mg} \mathrm{L}^{-1}$, em que as concentrações de auxina são frequentemente baixas se comparadas com as citocininas, tendo em vista a manutenção do balanço auxina/citocinina menor que 1 (GRATTAPAGLIA e MACHADO, 1998). Entretanto, devido a diferenças no comportamento das espécies, essas concentrações de reguladores de crescimento são variáveis.

Existem relatos sobre o sucesso dessa técnica na multiplicação de híbridos de Eucalyptus (BISHT et al., 1999; JOSHI et al., 2003; GLOCKE et al., 2006; NETTO et al., 2006), entretanto não há protocolo estabelecido para E. benthamii x E. dunnii. Além disso, a falta de opções de espécies de Eucalyptus tolerantes a geadas é uma das limitações da expansão de seu cultivo na Região Sul do Brasil, e tanto o E. benthamii quanto o E. dunnii se apresentam como alternativas potenciais para o empreendedor florestal nesses casos. Adicionalmente, a produção do híbrido interespecífico entre os materiais citados poderá proporcionar benefícios extras, ao associar as vantagens adaptativas e silviculturais das espécies parentais.

O trabalho teve como objetivo desenvolver um protocolo de estabelecimento, multiplicação e alongamento in vitro de E. benthamii x E. dunnii.

\section{MATERIAL E MÉTODOS}

\subsection{Material vegetal}

O material utilizado para a obtenção dos explantes foi proveniente de minicepas dos clones híbridos H12, H19 e H20 de Eucalyptus benthamii x Eucalyptus dunnii, obtidas pelo processo de estaquia convencional e conduzidas em minijardim clonal sob sistema semihidropônico de canaletão com areia média (Figura 1). 

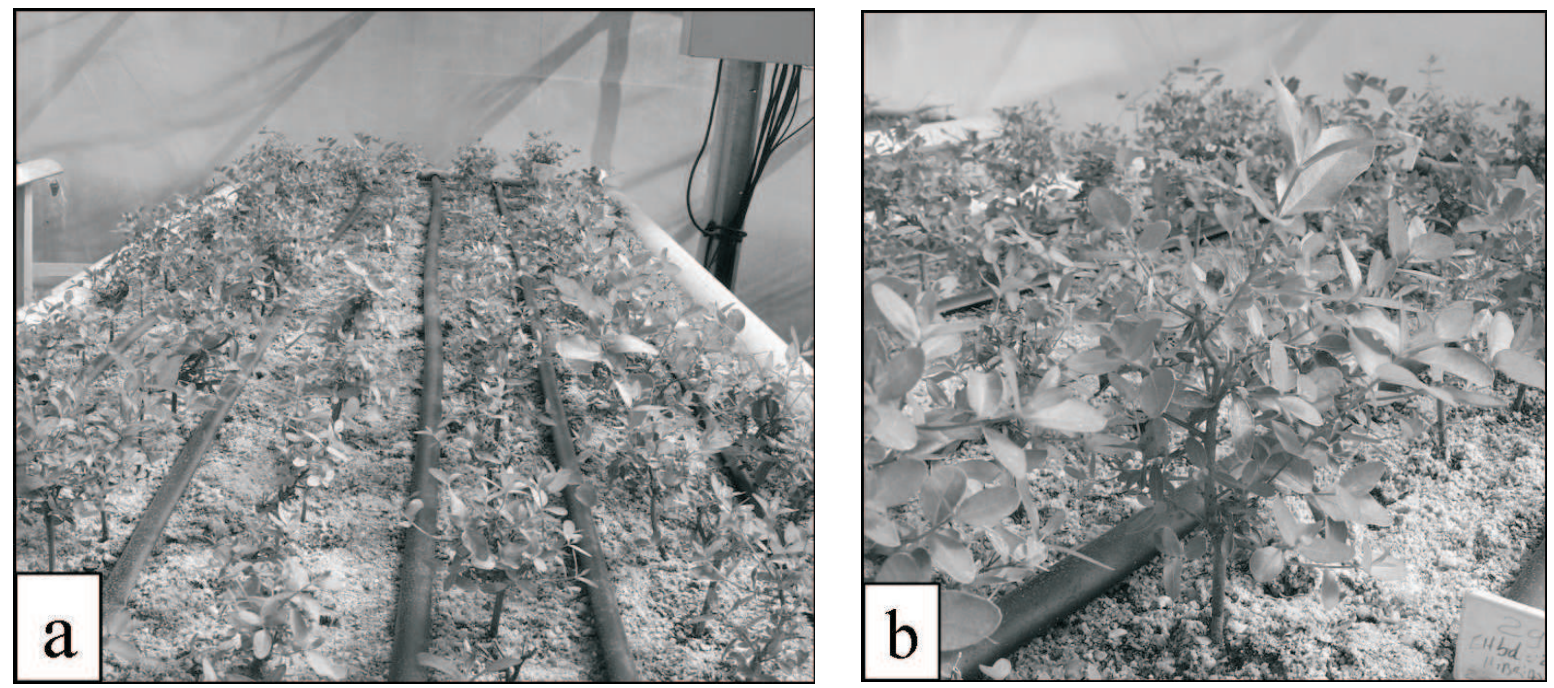

Fonte: Laboratório de Propagação de Plantas da Embrapa Florestas. Source: Embrapa Forests Plant Propagation Laboratory.

Figura 1 - Detalhe do minijardim clonal de E. benthamii x E. dunnii (a) e brotações aptas para a coleta (b). Figure $1-E$. benthamii x E. dunnii clonal minigarden (a) and buds apt for collection $(b)$.

Passados 20 dias após o plantio das mudas de estaquia com aproximadamente $15 \mathrm{~cm}$ de altura no sistema semi-hidropônico, procedeu-se à decepa da parte aérea para formar as minicepas. A decepa foi efetuada $5 \mathrm{~cm}$ acima da brotação de cada estaca enraizada, tomandose o cuidado de deixar no mínimo um par de folhas remanescentes por minicepa, para reduzir o estresse e facilitar a iniciação da brotação posterior, conforme metodologia descrita por Wendling (1999), constituindo, dessa forma, o minijardim clonal.

As minicepas foram conduzidas em estufa, recebendo diariamente por gotejamento, a uma vazão de $5 \mathrm{~L} \mathrm{~m}^{-2}$, solução nutritiva composta de monoamônio fosfato $\left(0,04 \mathrm{~g} \mathrm{~L}^{-1}\right)$, sulfato de magnésio $\left(0,40 \mathrm{~g} \mathrm{~L}^{-1}\right)$, nitrato de potássio $\left(0,44 \mathrm{~g} \mathrm{~L}^{-1}\right)$, sulfato de amônio $(0,31$ $\left.\mathrm{g} \mathrm{L}^{-1}\right)$, cloreto de cálcio $\left(0,79 \mathrm{~g} \mathrm{~L}^{-1}\right)$, ácido bórico $(2,88$ $\left.\mathrm{mg} \mathrm{L}^{-1}\right)$, sulfato de manganês $\left(3,70 \mathrm{mg} \mathrm{L}^{-1}\right)$, molibdato de sódio $\left(0,18 \mathrm{mg} \mathrm{L}^{-1}\right)$, sulfato de zinco $\left(0,74 \mathrm{mg} \mathrm{L}^{-1}\right)$ e hidroferro em pó $\left(81,80 \mathrm{mg} \mathrm{L}^{-1}\right)$. A condutividade elétrica da solução nutritiva foi mantida em $1,6 \mathrm{mS} \mathrm{m}^{-2}$ a 25 ${ }^{\circ} \mathrm{C}$ e o pH ajustado em 5,6 ( \pm 1$)$, corrigido com ácido muriático e $\mathrm{NaOH}(1 \mathrm{M})$.

\subsection{Estabelecimento in vitro}

Uma semana previamente a coleta das brotações dos clones foi aplicado fungicida Kumulus $\mathrm{DF}^{\circledR}$ (enxofre como princípio ativo) a $3 \mathrm{~g} \mathrm{~L}^{-1}(\mathrm{p} / \mathrm{v})$, conforme recomendações de Alfenas et al. (2004). As brotações utilizadas foram provenientes da terceira coleta (90 dias após a poda do ápice da minicepa), sendo transportadas em sacos de polietileno contendo solução de ácido ascórbico $1 \%(\mathrm{p} / \mathrm{v})$. Posteriormente, procedeu-se à retirada das folhas e lavagem superficial do material vegetal com água deionizada, para a remoção de partículas e poeira. Durante todo o processo, os equipamentos utilizados foram desinfestados com solução de álcool $70 \%$ (v/v).

Segmentos nodais contendo um par de gemas axilares sem as folhas e com $1,5 \mathrm{~cm}$ de comprimento foram imersos em solução de álcool $70 \%$ (v/v) por 15 seg, enxaguados com água deionizada e submetidos às concentrações de 0,$5 ; 1,0 ; 1,5 ;$ e $2,0 \%$ (v/v) de cloro ativo $(\mathrm{NaOCl})$ e acrescidas de Tween 20 (0,05\% v/v), durante $10 \mathrm{~min}$. Finalmente, os segmentos nodais foram lavados três vezes com água deionizada e autoclavada e inoculados verticalmente em tubos de ensaio cônicos de $15 \mathrm{~cm}$ x $2 \mathrm{~cm}$ contendo $10 \mathrm{~mL}$ do meio de cultura MS (MURASHIGE e SKOOG, 1962) suplementado com $250 \mathrm{mg} \mathrm{L}^{-1}$ de PVP 40, $30 \mathrm{~g} \mathrm{~L}^{-1}$ de sacarose, $6 \mathrm{~g} \mathrm{~L}^{-1} \mathrm{de}$ ágar e pH ajustado para 5,8. Após a inoculação, os explantes foram mantidos durante sete dias no escuro, para reduzir o processo oxidativo.

Aos 21 dias, avaliaram-se as contaminações fúngica e bacteriana e os explantes oxidados; dos explantes estabelecidos foram avaliados o número de folhas, o número de brotações e o comprimento total das brotações.

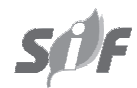

R. Árvore, Viçosa-MG, v.33, n.1, p.11-19, 2009 
O experimento foi conduzido no delineamento inteiramente casualizado em arranjo bifatorial $(3 \mathrm{x} 4)$, sendo os fatores constituídos por três clones: H12, H19 e H20; e quatro assepsias: 0,$5 ; 1,0 ; 1,5 ;$ e $2,0 \%$ de cloro ativo com cinco repetições compostas de cinco explantes cada uma.

\subsection{Multiplicação}

Brotações contendo de uma a duas gemas axilares, provenientes da fase de estabelecimento dos clones $\mathrm{H} 12, \mathrm{H} 19$ e H20, foram inoculadas em frascos de $7 \mathrm{~cm}$ x $5,5 \mathrm{~cm}$ contendo $40 \mathrm{~mL}$ do meio de cultura $1 / 2 \mathrm{MS}$ (MURASHIGE e SKOOG, 1962) suplementado com 0; 0,25; 0,50; 0,75; e 1,0 $\mathrm{mg} \mathrm{L}^{-1}$ de benzilaminopurina (BAP) e $0,01 \mathrm{mg} \mathrm{L}^{-1}$ de ácido naftalenoacético (ANA). Ao meio de cultura adicionaram-se, ainda, $250 \mathrm{mg} \mathrm{L}^{-1} \mathrm{de}$ PVP40, $30 \mathrm{~g} \mathrm{~L}^{-1}$ de sacarose e $6 \mathrm{~g} \mathrm{~L}^{-1}$ de ágar, sendo o pH ajustado para 5,8. Aos 30 dias, procedeu-se ao subcultivo dos explantes em novo meio de cultura. O número de gemas axilares formadas por explante foi avaliado aos 30 e 60 dias após a inoculação.

O experimento foi conduzido em delineamento inteiramente casualizado, testando-se cinco concentrações de BAP $(0 ; 0,25 ; 0,50 ; 0,75$; e 1,0 mg $\mathrm{L}^{-1}$ de BAP) com cinco repetições compostas de quatro explantes cada uma.

\subsection{Alongamento}

Explantes contendo de 10 a 20 brotações, obtidas na fase de multiplicação do clone $\mathrm{H} 12$, foram inoculados em frascos de $7 \mathrm{~cm}$ x 5,5 cm contendo $20 \mathrm{~mL}$ do meio de cultura 1/2MS (MURASHIGE e SKOOG, 1962) suplementado com 0; 0,25; 0,50; 0,75; e 1,0 $\mathrm{mg} \mathrm{L}^{-1} \mathrm{de}$ ANA e $0,05 \mathrm{mg} \mathrm{L}^{-1}$ de BAP. Adicionaram-se $250 \mathrm{mg}$ $\mathrm{L}^{-1}$ de PVP40, $15 \mathrm{~g} \mathrm{~L}^{-1}$ de sacarose e $6 \mathrm{~g} \mathrm{~L}^{-1}$ de ágar, sendo o pH ajustado para 5,8. Aos 30 dias, procedeuse ao subcultivo dos explantes em novo meio de cultura. O número de brotações alongadas e o comprimento total por explante foram avaliados aos 30 e 60 dias após a inoculação.

O experimento foi conduzido em delineamento inteiramente casualizado, testando-se cinco concentrações de ANA $(0 ; 0,25 ; 0,50 ; 0,75 ;$ e 1,0 mg $\mathrm{L}^{-1}$ de ANA), com cinco repetições compostas de quatro explantes cada uma.

\subsection{Condições de cultura}

A cada preparo do meio de cultura com água deionizada, o valor do $\mathrm{pH}$ foi se ajustando com $\mathrm{HCl}$
$(0,1 \mathrm{M})$ e $\mathrm{NaOH}(0,1 \mathrm{M})$, previamente à adição do ágar ao meio nutritivo, e então autoclavado na temperatura de $121^{\circ} \mathrm{C}\left(\cong 1,0 \mathrm{kgf} \mathrm{cm}^{-2}\right)$ durante $20 \mathrm{~min}$. Em todos os experimentos realizados, os explantes foram cultivados em sala de incubação com temperatura mantida em $26^{\circ} \mathrm{C}\left( \pm 2{ }^{\circ} \mathrm{C}\right)$, fotoperíodo de $16 \mathrm{~h}$ luz e luminosidade de $84 \mu \mathrm{mol} \mathrm{m} \mathrm{m}^{-2} \mathrm{~s}^{-1}$, fornecidas por lâmpadas fluorescentes branca-frias.

\subsection{Análise dos dados}

Os dados foram submetidos à análise de variância (ANOVA) $(p<0,01$ e $p<0,05)$, sendo as médias comparadas pelo teste de Tukey $(p<0,05)$ e por regressão polinomial $(\mathrm{p}<0,01$ e $\mathrm{p}<0,05)$. Utilizou-se o programa SOC (EMBRAPA, 1990) para a realização dos procedimentos estatísticos.

\section{RESULTADOS E DISCUSSÃO}

\subsection{Introdução in vitro}

Com base na ANOVA das características amostradas, pôde-se verificar que não existiu interação entre o fator clone em relação às diferentes concentrações de cloro ativo testadas na fase de estabelecimento, ou seja, os clones H12, H19 e H2O não diferiram quanto ao tratamento asséptico. Entretanto, existiu efeito significativo dos clones quanto à porcentagem de contaminação bacteriana, explantes oxidados e explantes estabelecidos aos 21 dias após a inoculação (Tabela 1).

Não houve efeito dos fatores testados para o porcentual da contaminação fúngica, obtendo-se média de 41,33\%. Quanto à contaminação bacteriana, o clone H19 apresentou o maior valor médio com $9 \%$ de contaminação, diferindo estatisticamente do H12 e H20, os quais apresentaram, respectivamente, $1 \%$ e ausência de contaminação para essa variável (Figura 2). Tornase prudente a identificação da fonte contaminante (fúngica ou bacteriana) durante o estabelecimento, a qual poderá auxiliar a estratégia de manejo fitossanitário no preestabelecimento in vitro a ser adotada na plantamatriz fornecedora de propágulos vegetativos. No caso deste estudo, a contaminação fúngica requer maior atenção, em que a execução de tratamentos mais criteriosos, como a aplicação de fungicidas nas minicepas previamente à coleta das brotações, poderá reduzir essa fonte de contaminação, auxiliando a maximização do processo de micropropagação do híbrido. 
Tabela 1 - Resultados da análise de variância da contaminação fúngica (Fun), bacteriana (Bac), explantes oxidados (Oxi), explantes estabelecidos (Est), número de folhas (NF), comprimento total das brotações (CB) e número de brotações por explante (NB) de híbridos de E. benthamii x E. dunnii, em função dos tratamentos testados aos 21 dias após a inoculação

Table 1 - Variance analysis results of the fungic contamination (Fun), bacterial contamination (Bac), oxidation explants $(O x i)$, healthy explants (Est), leaf number $(N F)$, total length of the buds $(C B)$ and number of buds per explants (NB) of E. benthamii $x$ E. dunnii hybrids in function of the treatments tested, at 21 days after inoculation

\begin{tabular}{|c|c|c|c|c|c|c|c|c|}
\hline \multirow[t]{3}{*}{ Causas da Variação } & \multirow[t]{3}{*}{ GL } & \multicolumn{7}{|c|}{ Quadrados Médios } \\
\hline & & Fun $^{(1)}$ & $\mathrm{Bac}^{(1)}$ & $\mathrm{Oxi}^{(1)}$ & Est ${ }^{(1)}$ & \multirow{2}{*}{$\begin{array}{c}\mathrm{NF}^{(2)} \\
\left(\operatorname{expl} .^{-1}\right)\end{array}$} & \multirow{2}{*}{$\begin{array}{l}\mathrm{CB}^{(2)} \\
(\mathrm{cm})\end{array}$} & \multirow{2}{*}{$\begin{array}{c}\mathrm{NB}^{(2)} \\
\left(\exp 1^{-1}\right)\end{array}$} \\
\hline & & \multicolumn{4}{|c|}{$(\%)$} & & & \\
\hline$\overline{\text { Clone (C) }}$ & 2 & $0,4157^{\mathrm{ns}}$ & $0,3028 * *$ & $0,1206 * *$ & $0,6047 * *$ & $0,0013^{\mathrm{ns}}$ & $0,0021^{\mathrm{ns}}$ & $0,0034^{\mathrm{ns}}$ \\
\hline Cloro $(\mathrm{Cl})$ & 3 & $0,1519^{\mathrm{ns}}$ & $0,0164^{\mathrm{ns}}$ & $0,0283^{\mathrm{ns}}$ & $0,1726^{\mathrm{ns}}$ & $0,0072^{\mathrm{ns}}$ & $0,0039^{\mathrm{ns}}$ & $0,0026^{\mathrm{ns}}$ \\
\hline $\mathrm{C} * \mathrm{Cl}$ & 6 & $0,0784^{\mathrm{ns}}$ & $0,0195^{\mathrm{ns}}$ & $0,0908^{\mathrm{ns}}$ & $0,1045^{\mathrm{ns}}$ & $0,0041^{\mathrm{ns}}$ & $0,0014^{\mathrm{ns}}$ & $0,0011^{\mathrm{ns}}$ \\
\hline Resíduo & 48 & 0,1444 & 0,0358 & 0,0246 & 0,1059 & 0,0046 & 0,0022 & 0,0036 \\
\hline Média & - & 41,33 & 3,33 & 3,00 & 52,33 & 5,48 & 0,78 & 1,75 \\
\hline $\mathrm{CV}(\%)$ & - & 24,42 & 23,92 & 19,97 & 18,81 & 9,22 & 17,05 & 14,43 \\
\hline
\end{tabular}

${ }^{n s} \mathrm{~F}$ não-significativo a $5 \%$ de probabilidade; $* *$ F significativo a $1 \%$ de probabilidade. ${ }^{(1)}$ Dados transformados por $\sqrt{p+0,5} \mathrm{e}^{(2)}$ por $\sqrt{\frac{p}{10}}$, em virtude de não apresentarem normalidade pelo teste de Lilliefors a $5 \%$ de probabilidade. $\mathrm{GL}=$ graus de liberdade, $\mathrm{CV}=$ coeficiente de variação. expl. $=$ explante.

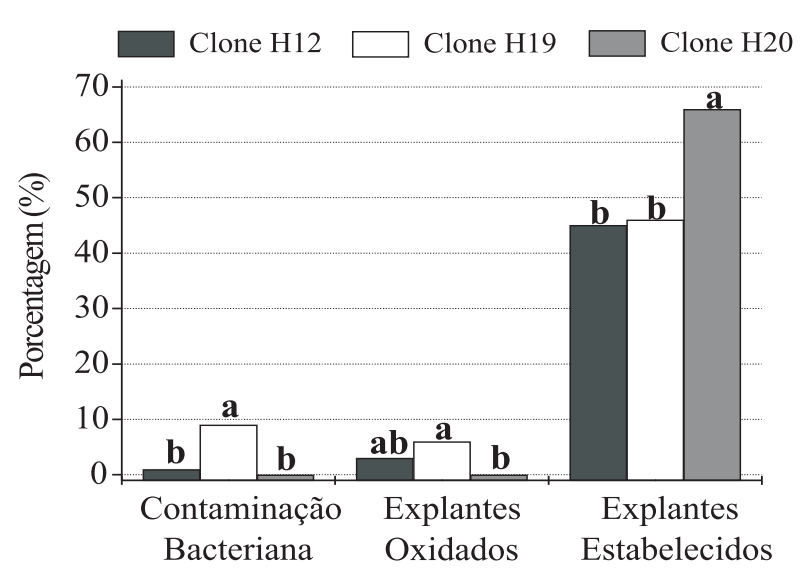

Figura 2 - Valores médios da contaminação bacteriana, oxidação e explantes estabelecidos de E. benthamii x E. dunnii aos 21 dias após a inoculação. Médias seguidas por uma mesma letra não diferem estatisticamente pelo teste de Tukey a $5 \%$ de probabilidade de erro.

Figure 2-Mean values of bacterial contamination, oxidation and established healthy explants of E. benthamii $x$ E. dunnii, at 21 days after inoculation.Means followed by the same letter do not differ significantly by the Tukey test, at $5 \%$ probability level.

Houve diferença significativa entre as taxas de oxidação dos clones H19 e H20, com 6\% e ausência de oxidação, respectivamente. Já o clone H12 não diferiu significativamente dos outros, apresentando valor médio de $3 \%$ (Figura 2).

Aos 21 dias após a inoculação, os clones H12 e H19 não diferiram quanto à porcentagem de explantes estabelecidos, apresentado valores de $45 \%$ e $46 \%$, respectivamente. Porém, o clone $\mathrm{H} 20$ exibiu o maior valor médio de explantes estabelecidos (66\%), diferindo significativamente dos demais (Figura 2).

Joshi et al. (2003), ao trabalharem com segmentos nodais de 2 a $3 \mathrm{~cm}$ de comprimento, os quais foram coletados de árvores de E. tereticornis x E. grandis de 30 anos de idade, obtiveram 50\% de segmentos nodais não contaminados quando expostos durante $20 \mathrm{~min}$ na concentração de $30 \%$ (v/v) de $\mathrm{NaOCl}_{2}$. Os resultados foram semelhantes aos encontrados neste estudo com o híbrido, porém o tempo de exposição foi superior, possivelmente por se tratar de material proveniente diretamente do campo, os quais necessitam de maior critério de desinfestação para o estabelecimento in vitro (ALFENAS et al., 2004).

Quando se utiliza material vegetativo diretamente do campo, os tratamentos desinfetantes são mais criteriosos, em virtude de os explantes apresentarem maiores níveis de contaminação, e geralmente as concentrações e tempos de exposições aos agentes desinfetantes são maiores (GRATTAPAGLIA e MACHADO, 1998), em comparação com os explantes provenientes de ambientes protegidos. Para esses explantes, Alfenas et al. (2004) recomendaram a concentração de $0,5 \%$ de cloro ativo durante $20 \mathrm{~min}$ para segmentos nodais mais lignificados e $0,3 \%$ de cloro ativo durante 2 min para segmentos nodais mais tenros. Além disso, Grattapaglia e Machado (1998) ressaltaram que o estado fisiológico da planta-matriz de 
onde são retirados os explantes apresenta grande influência no posterior comportamento das culturas. Esse fator pode ter influenciado a resposta dos clones quanto aos tratamentos testados, pois os explantes foram provenientes de minicepas cultivadas em minijardim clonal manejadas em sistema semi-hidropônico, o qual apresentou homogeneidade das condições de manejo fitossanitário. Segundo Campinhos et al. (1999), as vantagens mais relevantes desse sistema estão ligadas ao controle mais efetivo de todo o processo, como maior controle da irrigação, nutrição, tratos culturais e pragas e doenças.

Devido ao efeito não-significativo entre os tratamentos de hipoclorito de sódio testados, recomendase a concentração de $0,5 \%$ de cloro ativo para a desinfestação de explantes do material híbrido proveniente de minijardim clonal cultivado em leito de areia.

\subsection{Multiplicação}

Embora não tenha ocorrido diferença significativa quanto ao número de folhas, comprimento e número de brotações entre os genótipos durante o estabelecimento (Tabela 1), os clones H19eH20 apresentaram comportamento recalcitrante na fase de multiplicação, com elevada taxa de oxidação, fator esse que impediu os cultivos subsequentes. Somente o clone H12 respondeu a essa fase, sendo possível determinar as faixas das concentrações de reguladores de crescimento mais eficientes para a proliferação de gemas axilares. Segundo George (1993) e Hartmann et al. (2002), cada material genético pode responder diferenciadamente quanto à propagação vegetativa. Essa hipótese foi constatada neste estudo durante a multiplicação. Possivelmente, serão necessários ajustes do meio de cultura para os clones H19 e H20, os quais poderão promover melhores resultados ao cultivo in vitro.

Aos 30 e 60 dias após a inoculação, constatou-se comportamento polinomial cúbico quanto à multiplicação de gemas do clone H12 (Tabela 2). Aos 30 dias, o ponto crítico da concentração de BAP ficou em torno de 0,31 $\mathrm{mg} \mathrm{L}^{-1}$, correspondendo a uma produção de 6,9 gemas por explante (Figura 3). Esse comportamento foi semelhante aos 60 dias, quando o ponto crítico de BAP foi de 0,30 $\mathrm{mg} \mathrm{L}^{-1}$, porém ocorreu elevado acréscimo na taxa de multiplicação, correspondendo a uma estimativa de 20,2 gemas por explante nessa concentração de BAP (Figura 3). Com base nas interpretações das equações ajustadas, pode-se inferir que a faixa situada entre 0,25 e $0,50 \mathrm{mg}$ $\mathrm{L}^{-1}$ de BAP resultou nos melhores valores quanto ao número de gemas emitidas do material híbrido avaliado.
Tabela 2 - Resumo da análise de variância com decomposição dos tratamentos em regressão polinomial do número médio de gemas emitidas por explante (NG) do clone $\mathrm{H} 12$ de Eucalyptus benthamii x Eucalyptus dunnii, aos 30 e 60 dias após a inoculação, em função dos tratamentos de BAP

Table 2 - Variance analysis results with decomposition of the treatments in polynomial regression, for the mean number of buds per explant $(N G)$ of the Eucalyptus benthamiix Eucalyptus dunnii H12 clone, at 30 and 60 days after inoculation in function of the BAP treatments

\begin{tabular}{|c|c|c|c|}
\hline \multirow[t]{2}{*}{$\begin{array}{l}\text { Causas da } \\
\text { Variação }\end{array}$} & \multirow[t]{2}{*}{ GL } & \multicolumn{2}{|c|}{$\begin{array}{c}\text { Quadrados Médios } \\
\text { NG }\end{array}$} \\
\hline & & $\begin{array}{c}30 \text { dias } \\
\left(\text { explante }{ }^{-1}\right)\end{array}$ & $\begin{array}{c}60 \text { dias } \\
\left(\text { explante }{ }^{-1}\right)\end{array}$ \\
\hline$\overline{\mathrm{BAP}}$ & 4 & $22,56 * *$ & $327,34 * *$ \\
\hline $1^{\circ} \mathrm{grau}$ & 1 & $0,32 \mathrm{~ns}$ & $67,28 *$ \\
\hline $2^{\circ} \mathrm{grau}$ & 1 & $51,43 * *$ & $716,80 * *$ \\
\hline $3^{\circ} \mathrm{grau}$ & 1 & $36,98 * *$ & $518,42 * *$ \\
\hline Resíduo & 20 & 0,78 & 8,18 \\
\hline Média & - & 4,08 & 8,96 \\
\hline $\mathrm{CV}_{\text {exp. }}(\%)$ & - & 21,65 & 25,92 \\
\hline$\overline{\mathrm{SQM}}$ & - & $88,73 * *$ & $1.302,50 * *$ \\
\hline SQT & - & $90,24 * *$ & $1.309,36 * *$ \\
\hline $\mathrm{R}^{2}$ & - & $0,98 * *$ & $0,99 * *$ \\
\hline
\end{tabular}

ns Valor de F não-significativo a 5\% de probabilidade de erro.

* e ** Valor de F significativo a 5\% e $1 \%$ de probabilidade de erro, respectivamente. $\mathrm{GL}=$ graus de liberdade, $\mathrm{CV}=$ coeficiente de variação, $\mathrm{SQM}=$ soma de quadrados do modelo, $\mathrm{SQT}=$ soma de quadrados do tratamento e $\mathrm{R}^{2}$ = coeficiente de determinação.

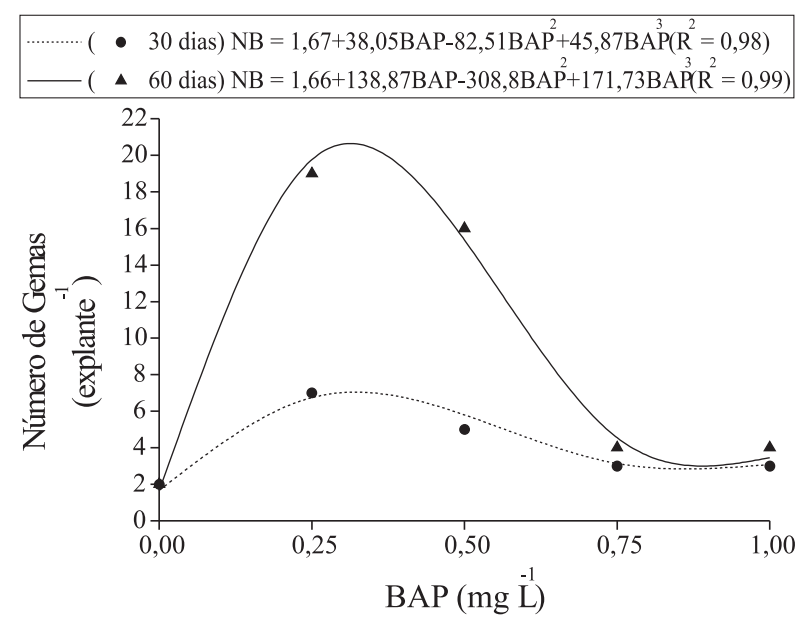

Figura 3-Número de gemas emitidas por explante do clone $\mathrm{H} 12$ de E. benthamii x E. dunnii, aos 30 e 60 dias após a inoculação, em função dos tratamentos de BAP.

Figure 3 -Mean number of buds per explant of clone $\mathrm{H} 12$ of E. benthamii $x$ E. dunnii, at 30 and 60 days after inoculation in function of the BAP treatments. 
Em condições semelhantes de cultivo, Gomes e Canhoto (2003) utilizaram concentrações de 0,9 $\mu \mathrm{M}$ de BAP $\left(\cong 0,20 \mathrm{mg} \mathrm{L}^{-1}\right)$ combinado com $0,05 \mu \mathrm{M}$ de ANA $\left(\cong 0,01 \mathrm{mg} \mathrm{L}^{-1}\right)$ em $1 / 2 \mathrm{MS}$ para proliferação de gemas de E. nitens Maiden. Após três subcultivos, obtiveram apenas 2,25 brotos por explante, contudo os resultados foram promissores devido à recalcitrância apresentada pelo material. Graça et al. (2001), ao compararem o efeito de BAP e Thidiazuron (TDZ) na multiplicação in vitro de brotações de E. dunnii, relataram que o BAP apresentou efeito superior quanto à produção de brotações, além de induzir baixa formação de calo. Joshi et al. (2003) obtiveram de 20 a 25 brotações por explante somente aos 150 dias em meio MS na concentração de $1 \mathrm{mg} \mathrm{L}^{-1}$ de BAP combinado com $1 \mathrm{mg} \mathrm{L}^{-1}$ de ANA para E. tereticornis $\mathrm{x}$ E. grandis. Resultados semelhantes foram obtidos por Bisht et al. (1999) em E. tereticornis $\mathrm{x}$ E. calmadulensis e por Sharma e Ramamurthy (2000) em E. tereticornis em meio MS suplementado com 1 $\mathrm{mg} \mathrm{L}^{-1}$ de BAP e $1 \mathrm{mg} \mathrm{L}^{-1}$ de ANA.

Concentrações de BAP acima de $0,75 \mathrm{mg} \mathrm{L}^{-1}$ não resultaram em efeitos positivos quanto à proliferação de gemas (Figura 3), e na concentração de $1 \mathrm{mg} \mathrm{L}^{-1}$ de BAP, além de ter apresentado sintomas de hiperhidricidade, houve oxidação dos explantes do clone
H12. Segundo Alfenas et al. (2004), concentrações elevadas de BAP podem resultar em acúmulo desse regulador de crescimento nos tecidos e prejudicar o posterior desenvolvimento das brotações, fato que pode ter influenciado a resposta obtida nas concentrações superiores a $0,75 \mathrm{mg} \mathrm{L}^{-1}$ de BAP.

\subsection{Alongamento}

$\mathrm{Na}$ fase de alongamento das brotações do H12 existiu comportamento polinomial cúbico aos 30 dias. Porém, ao cultivar os explantes por mais 30 dias nas mesmas condições, houve comportamento quadrático (Tabela 3). Aos 60 dias, a estimativa do ponto crítico de $0,49 \mathrm{mg} \mathrm{L}^{-1}$ de ANA correspondeu a 3,8 brotos alongados por explante (Figura 4). Com base na interpretação da equação ajustada aos 60 dias, podese inferir que as concentrações situadas entre 0,25 e $0,75 \mathrm{mg} \mathrm{L}^{-1}$ de ANA resultaram nos melhores valores do número de brotações alongadas por explante do clone H12.

O comprimento das brotações não variou em função da concentração de ANA em ambas as épocas de avaliação, apresentando valores médios de 1,1 e 2,4 cm, respectivamente, aos 30 e 60 dias após a inoculação (Tabela 3).

Tabela 3 - Resumo da análise de variância com decomposição dos tratamentos em regressão polinomial do número de brotações alongadas por explante (BAE) e do comprimento das brotações por explante (CB) do clone $\mathrm{H} 12$ de E. benthamii x E. dunnii, aos 30 e 60 dias após a inoculação, em função dos tratamentos de ANA

Table 3 - Variance analysis results with decomposition of the treatments in polynomial regression, for the number of elongated shoots per explant (BAE) and shoot length per explant $(C B)$ of the Eucalyptus benthamii $x$ Eucalyptus dunnii H12 clone, at 30 and 60 days after inoculation in function of the NAA treatments

\begin{tabular}{|c|c|c|c|c|c|}
\hline \multirow[t]{3}{*}{ Causas da Variação } & \multirow[t]{3}{*}{ GL } & \multicolumn{4}{|c|}{ Quadrados Médios } \\
\hline & & \multicolumn{2}{|c|}{$\mathrm{BAE}$} & \multicolumn{2}{|c|}{$\mathrm{CB}$} \\
\hline & & $\begin{array}{c}30 \text { dias } \\
\left(\text { explante }^{-1}\right)\end{array}$ & $\begin{array}{c}60 \text { dias } \\
\left(\text { explante }^{-1}\right)\end{array}$ & 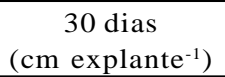 & 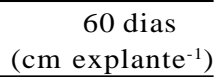 \\
\hline$\overline{\mathrm{ANA}}$ & 4 & $0,96 *$ & $6,56 * *$ & $0,0390^{\mathrm{ns}}$ & $0,848^{\mathrm{ns}}$ \\
\hline $1^{\circ} \mathrm{grau}$ & 1 & $0,00^{\mathrm{ns}}$ & $0,18^{\mathrm{ns}}$ & $0,0882 \mathrm{~ns}$ & $2,000^{\mathrm{ns}}$ \\
\hline $2^{\circ} \mathrm{grau}$ & 1 & $0,91^{\mathrm{ns}}$ & $19,56 * *$ & $0,0001^{\mathrm{ns}}$ & $1,209 \mathrm{~ns}$ \\
\hline $3^{\circ} \mathrm{grau}$ & 1 & $2,00 * *$ & $5,12^{\mathrm{ns}}$ & $0,0098^{\mathrm{ns}}$ & $0,180^{\mathrm{ns}}$ \\
\hline Resíduo & 20 & 0,22 & 1,24 & 0,085 & 1,010 \\
\hline Média & - & 1,48 & 2,72 & 1,1 & 2,4 \\
\hline $\mathrm{CV}_{\text {exp. }}(\%)$ & - & 21,69 & 22,94 & 26,54 & 22,23 \\
\hline$\overline{\mathrm{SQM}}$ & - & $2,91 *$ & $19,74 * *$ & - & - \\
\hline SQT & - & $3,84 *$ & $26,24 * *$ & $0,156^{\mathrm{ns}}$ & $3,392 \mathrm{~ns}$ \\
\hline $\mathrm{R}^{2}$ & - & $0,76 *$ & $0,75 * *$ & - & - \\
\hline
\end{tabular}

${ }^{\mathrm{ns}}$ Valor de F não-significativo a $5 \%$ de probabilidade de erro.

* e ** Valor de F significativo a 5\% e 1\% de probabilidade de erro, respectivamente. GL = graus de liberdade, $\mathrm{CV}=$ coeficiente de variação, $\mathrm{SQM}=$ soma de quadrados do modelo, SQT = soma de quadrados do tratamento e $\mathrm{R}^{2}=$ coeficiente de determinação. 


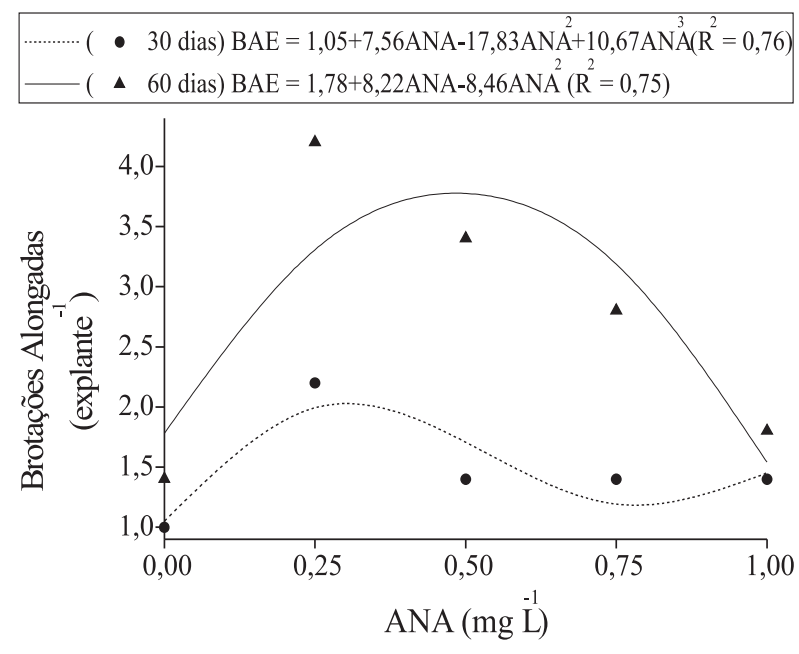

Figura 4-Número médio de brotações alongadas por explante (a) e comprimento médio das brotações alongadas por explante (b) do clone $\mathrm{H} 12$ de E. benthamii x E. dunnii, aos 30 e 60 dias após a inoculação, em função dos tratamentos de ANA.

Figure 4-Mean number of elongated shoots per explant (a), average length of the elongated buds per explant (b) of clone H12 of E. benthamii $x E$. dunnii, at 30 and 60 days after inoculation in function of ANA treatments.

Para este estudo, na concentração de $1 \mathrm{mg} \mathrm{L}^{-1} \mathrm{de}$ ANA foi observada indução de calo, resultando em efeito negativo no alongamento das brotações. Grattapaglia e Machado (1998) afirmaram que concentrações excessivas de auxina podem favorecer demasiadamente o enraizamento ou a formação de calo, confirmando essa hipótese neste estudo.

Joshi et al. (2003) observaram multiplicação seguida de alongamento das brotações de árvores de 30 anos de idade de E. tereticornis x E. grandis em meio MS. O comprimento médio das brotações alongadas foi de 2,5 a $3 \mathrm{~cm}$ durante 15 dias após a inoculação em meio suplementado com $1 \mathrm{mg} \mathrm{L}^{-1}$ de BAP e $0,4 \mathrm{mg} \mathrm{L}^{-1} \mathrm{de}$ $\mathrm{GA}_{3}$. Bisht et al. (1999), ao trabalharem com E.tereticornis x E. calmadulensis, também observaram multiplicação seguida de alongamento após um período de 120 dias de cultivo em meio MS suplementado com BAP e ANA. A partir desse período até 180 dias de cultivo em meio MS ocorreu alongamento em todos os tratamentos de BAP e ANA, resultando, no geral, em brotos de 2 a $3,5 \mathrm{~cm}$ de comprimento.

Embora tenha ocorrido baixo número de brotações alongadas do clone H12 durante as épocas de avaliação, as brotações mostraram-se vigorosas, o que indica boas perspectivas quanto às condições de cultivo in vitro desse material genético. Futuramente, variações nas relações de BAP e ANA e, ou, testes com outros reguladores de crescimento e meios de cultura poderão aprimorar a técnica e expressar resultados mais satisfatórios.

\section{CONCLUSÕES}

Os clones estudados não apresentaram comportamento distinto em relação às concentrações de cloro ativo estudadas, obtendo-se até $66 \%$ de estabelecimento do clone $\mathrm{H} 20$ e $45 \%$ e $46 \%$ dos clones H12 e H19, respectivamente, aos 21 dias após a inoculação, sendo recomendada a concentração de $0,5 \%$ de cloro ativo para a desinfestação dos explantes.

A faixa da concentração de BAP que resultou em maior taxa de proliferação de gemas axilares por explante do clone $\mathrm{H} 12$ foi estabelecida entre 0,25 e $0,50 \mathrm{mg} \mathrm{L}^{-1}$, aos 60 dias após a inoculação.

Aos 60 dias após a inoculação, a faixa entre 0,25 e $0,75 \mathrm{mg} \mathrm{L}^{-1}$ de ANA promoveu o maior número de brotações alongadas por explante do clone H12, com comprimento médio de $2,4 \mathrm{~cm}$.

O protocolo ora ajustado para o clone $\mathrm{H} 12$ de $E$. benthamii x E. dunnii pode ser considerado eficiente para a sua micropropagação. Contudo, ajustes nas fases de multiplicação e alongamento de materiais genéticos H19 e H20 serão necessários e complementares para o desenvolvimento de um protocolo eficiente para o cultivo in vitro.

\section{REFERÊNCIAS}

AlfEnAS, A. C. et al. Clonagem e doenças do eucalipto. Viçosa, MG: Universidade Federal de Viçosa, 2004. 442p.

ALVES, E. C. S. C.; XAVIER, A.; OTONI, W. C. Organogênese in vitro a partir de explante caulinar na regeneração de clones de Eucalyptus grandis W. Hill ex Maiden x E. urophylla S. T. Blake. Revista Árvore, v.28, n.5, p.643-653, 2004.

BISHT, P. et al. Micropropagation of newly produced $\mathrm{F}_{1}$ hybrid of Eucalyptus (E. tereticornis Sm. x E. camaldulensis Dehn. Southern Form). Silvae Genetica, v.48, n.2, p.104-108, 1999. 
CAMPINHOS, E. N. et al. Hidrojardim clonal Champion: uma otimização na produção de mudas de eucalipto. Silvicultura, v.19, n.80, p.42-46, 1999.

DEL PONTE, E. M. et al. Multiplicação e enraizamento in vitro de Eucalyptus globulus subsp. globulus Labill. Revista Árvore, v.25, n.1, p.1-8, 2001.

EMPRESA BRASILEIRA DEPESQUISA AGROPECUÁRIA - EMBRAPA. Programa SOC - Software Científico, Versão 2.1. Campinas: Embrapa Informática Agropecuária, 1990.

GEORGE, E. F. Plant propagation by tissue culture. 2.ed. Edington: Exegetics, 1993. v. $1.574 \mathrm{p}$.

GLOCKE, P. et al. Micropropagation of juvenile tissue of Eucalyptus erythronema x Eucalyptus stricklandii Cv. "Urrbrae Gem". In Vitro

Cellular and Developmental BiologyPlant, v.42, n.2, p.139-143, 2006.

GOMES, F.; CANHOTO, J. M. Micropropagation of Eucalyptus nitens Maiden (Shining Gum). In Vitro Cellular and Developmental Biology-Plant, v.39, n.3, p.316-321, 2003.

GRAÇA, M. E. C. et al. Efeitos das citocininas benzilamino purina e thidiazuron na multiplicação "in vitro" de brotações de Eucalyptus dunnii Maid. Boletim de Pesquisa Florestal, n.43, p.107-112, 2001.

GRATTAPAGLIA, D. \& MACHADO, M. A. Micropropagação. In: TORRES, A. C.; CALDAS, L. S.; BUSO, J. A. (Eds.) Cultura de tecidos e transformação genética de plantas. Brasília: Embrapa-SPI/Embrapa-CNPH, 1998. p.183-260.

HARTMANN, H. T. et al. Plant propagation: principles and practices. 7.ed. New Jersey: Prentice-Hall, 2002. 880p.

JOSHI, I. et al. In vitro clonal propagation of mature Eucalyptus $\mathrm{F}_{1}$ hybrid (Eucalyptus tereticornis Sm. x E. grandis Hill ex Maiden). Silvae Genetica, v.52, n.3-4, p.110-113, 2003.
MERKLE, S. A.; NAIRN, C. J. Hardwood tree biotechnology. In Vitro Cellular and Developmental Biology-Plant, v.41, n.5, p.602-619, 2005.

MURASHIGE, T.; SKOOG, F. A revised medium for rapid growth and bioassays with tobacco tissue cultures. Physiologia Plantarum, v.15, p.473-497, 1962.

NEHRA, N. S. et al. A. Invited review: forest biotechnology: innovative methods, emerging opportunities. In Vitro Cellular and Developmental Biology-Plant, v.41, n.6, p.701-717, 2005.

NETTO, A. B. P. et al. hooting control in Eucalyptus grandis $\mathrm{x}$ E. urophylla hybrid: comparative effects of 28-homocastasterone and a 5 a-monofluoro derivative. Plant Cell, Tissue and Organ Culture, v. 86, n.3, p.329-335, 2006.

SHARMA, S. K.; RAMAMURTHY, V. Micropropagation of 4-year-old elite Eucalyptus tereticornis trees. Plant Cell Reports, v.19, n.5, p.511-518, 2000.

TITON, M. et al. Efeito do AIB no enraizamento de miniestacas e microestacas de clones de Eucalyptus grandis W. Hill ex Maiden. Revista Árvore, v.27, n.1, p.1-7, 2003.

WATT, M. P. et al. In vitro field collection techniques for Eucalyptus micropropagation. Plant Cell, Tissue and Organ Culture, v.75, n.3, p.233-240, 2003.

WEndling, I. Propagação clonal de híbridos de Eucalyptus spp. por miniestaquia. 1999. 77f. Dissertação (Mestrado em Ciência Florestal) - Universidade Federal de Viçosa, Viçosa, MG, 1999.

XAVIER, A.; COMÉRIO, J. Enraizamento "ex vitro" de gemas de Eucalyptus spp. multiplicadas e alongadas "in vitro". Scientia Forestalis, n.51, p.29-36, 1997.

XAVIER, A.; COMÉRIO, J. Microestaquia: uma maximização da micropropagação de Eucalyptus. Revista Árvore, v.20, n.1, p.9-16, 1996. 